\title{
IRON DEFICIENCY IN ADOLESCENT FEMALE DANCERS
}

\author{
E. MAHLAMÄKI and S. MAHLAMÄKI \\ Department of Clinical Chemistry and Department of Physiology, University of Kuopio, Finland
}

\section{ABSTRACT}

The iron balance of 25 adolescent dancers and 23 control females of the same age were studied. The concentrations of fasting blood haemoglobin, serum iron, serum transferrin and serum ferritin were determined. Iron supplementation (ferrous sulphate corresponding to $100 \mathrm{mg}$ of elemental iron per day) was instigated if body iron stores were low (serum ferritin $<30 \mu \mathrm{g} .1-1)$. Blood samples were drawn again after ten weeks.

Low haemoglobin concentration (blood haemoglobin $<125 \mathrm{g.l}-1$ ) was more prevalent among dancers than among control subjects. Reduced iron stores as well as completely absent iron stores (serum ferritin concentration $<12 \mu \mathrm{g} .1-1$ ) were equally common in both groups (25\% of the subjects). Iron supplementation reduced the number of anaemic girls from 16 to 4 and the highly significant difference in haemoglobin level between the treated and untreated groups disappeared. Ten weeks of iron therapy was not, however, long enough to increase iron stores.

Key words: Iron deficiency, Girls, Dancers

\section{INTRODUCTION}

Iron deficiency is known to affect at least $10-20 \%$ of women of fertile age in the western countries (Cook et al, 1976; Fairbanks and Beutler, 1983). Nutritional iron and individual iron status regulate iron absorption in man (Lynch and Morck, 1983). According to the multicentre study of Finnish children and adolescents the nutritional iron requirements are not met in small children and 12-18-year-old girls (Räsänen et al, 1985).

Anaemia is a late and insensitive indicator of iron deficiency (Lynch and Morck, 1983). For earlier recognition of a negative iron balance serum ferritin estimation is needed (Cavill, 1982). Other tests such as free erythrocyte protoporphyrin can be used as well (Lynch and Morck, 1983).

Fertile women and physically active children during growth are prone to iron deficiency (Remes, 1985). The prevalence and aetiology of iron deficiency in athletes has been studied quite extensively (for instance Pakarinen and Heikkinen, 1985; Hunding et al, 1981; Haymes et al, 1986). It seems to be of interest to diagnose iron deficiency before overt anaemia develops to secure an optimal physical performance (Finch et al, 1979). Outside of these risk groups of iron deficiency, "sports anaemia" is often due to increased plasma volume rather than lowered total haemoglobin content (Hallberg and Magnusson, 1984), although Hunding and co-workers have described a prevalence of iron deficiency of more than $50 \%$ in long distance runners (Hunding et al, 1981).

Dancers need to be both slim and fit. For professional dancers, the sum of four skinfolds is lower than normal (unpublished observation, Mahlamäki et al). Nutritional problems of dancers have been discussed and it seems evident that the requirements of iron and other minerals are not always met in dancers probably due to the low energy intake (Saris and Brouns, 1986).

The aim of this work was to make a comparative study of the occurrence of iron deficiency in adolescent female dancers and in a group of age-matched control subjects.

Address for correspondence:

Dr. S. Mahlamäki

University of Kuopio

Po B 6

SF-70211

Finland
The effect of iron supplementation in increasing the body iron stores was also studied.

\section{MATERIALS AND METHODS}

The participants of the study were high school girls (average age 17.3 years) attending the music and dance high school in Kuopio, Finland. There were 31 (final number 25) dancers (ballet and modern dance) and 28 (23) music students as their control subjects. In order to evaluate their iron status fasting blood haemoglobin concentration, serum iron and transferrin concentrations and serum ferritin concentration were determined by standard laboratory methods. Iron supplementation (ferrous sulphate equivalent to $100 \mathrm{mg}$ of elemental iron per day) was instigated if body iron stores were reduced or completely absent. Serum ferritin concentration of $30 \mu \mathrm{g} . \mathrm{I}^{-1}$ was considered to express reduced iron stores and $12 \mu \mathrm{g} . \mathrm{I}^{-1}$ was the cut off level for absent storage iron (Remes, 1985).

Blood samples were drawn again after ten weeks. The iron supplementation was discontinued one week before the blood samples were obtained. The laboratory methods were the same as for the baseline measurements. A questionnaire and a personal interview were used to obtain information about the amount of exercise and the overall health status including menstrual regularity.

Differences between two independent frequency distributions were tested by chi-square test. Statistical significance of the differences in the means of the continuous variables were tested by t-test. A paired t-test was used to test the statistical significance of the possible changes in the parameters analysed.

\section{RESULTS}

The dancers spent more $(p<0.05)$ time in physical activities than their controls ( 9 vs. 2 hours weekly). The general health status and menstrual regularity were the same in both groups. Low haemoglobin level ( $\left.\mathrm{Hb}<125 \mathrm{~g} . \mathrm{I}^{-1}\right)$ was more $(p<0.05)$ prevalent in dancers than in the control group (Fig. 1). This was invariably accompanied by reduced serum ferritin concentration, while serum iron and transferrin concentrations varied. A clear iron deficiency anaemia (low haemoglobin level, low serum iron and increased transferrin concentration) was present in $15 \%$ of the dancers, but not in any of the control subjects. Serum ferritin concentration was markedly reduced in these cases.

There were many individuals with reduced iron stores 


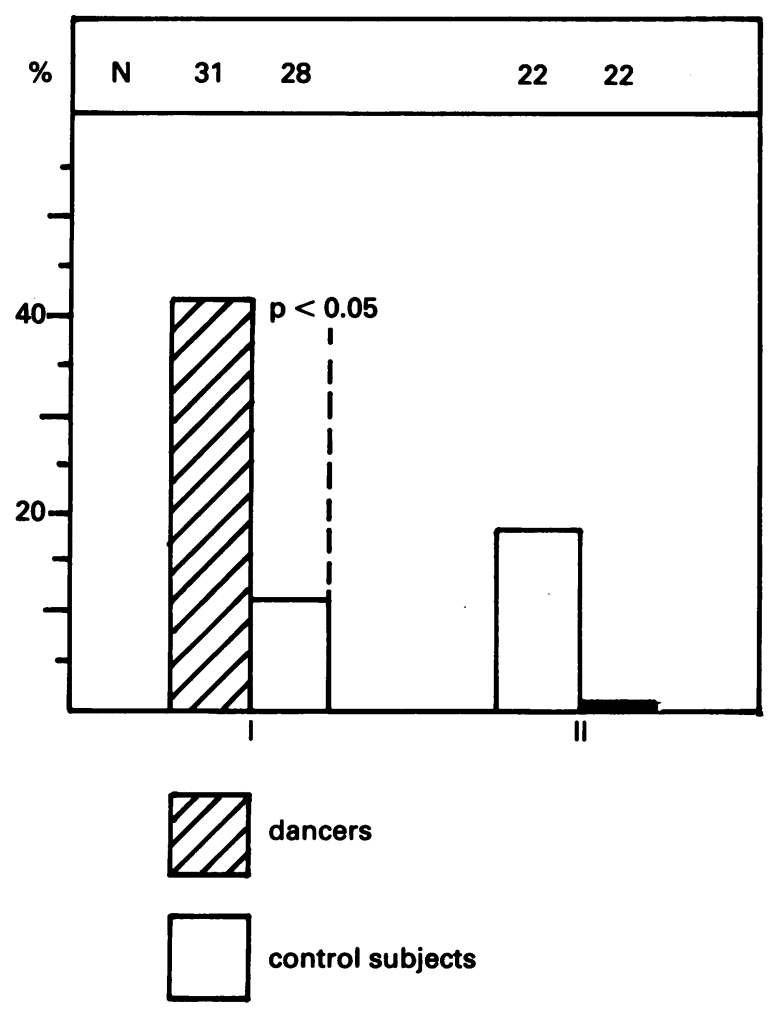

Fig. 1: The prevalence (\%) of low haemoglobin concentration ( $<125 \mathrm{~g} / 1)$ of adolescent female dancers and their control subjects before (I) and after (II) the iron supplementation for ten weeks.

(serum ferritin concentration less than $30 \mu \mathrm{g} . \mathrm{I}^{-1}$ ) in both groups (Fig. 2). Also completely absent iron stores were equally common in both groups ( $25 \%$ of the subjects).

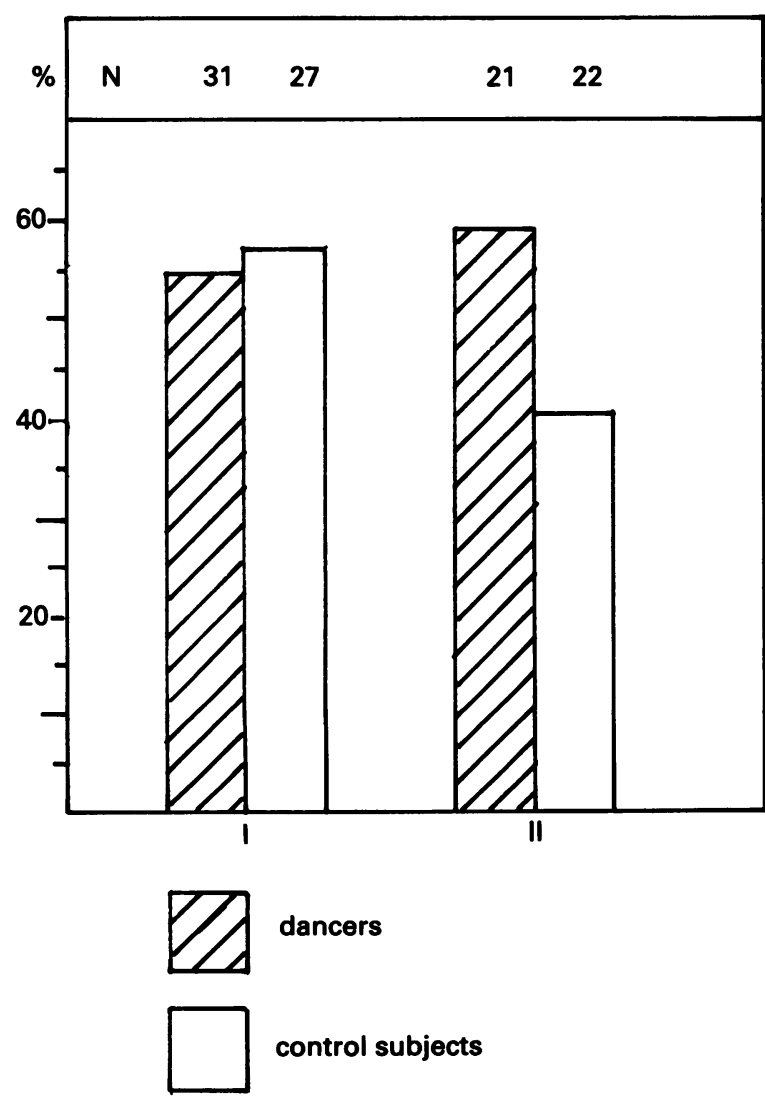

Fig. 2: The prevalence (\%) of reduced iron stores (S-ferritin $<30 \mu g /$ ) before (I) and after (II) the iron supplementation for ten weeks.
Iron supplementation reduced the number of anaemic girls from 16 to 4 , and the highly significant difference of haemoglobin levels between the treated and untreated groups disappeared (Fig. 1). However, iron treatment did not affect the number of girls with reduced iron stores (Fig. 2).

\section{DISCUSSION}

The prevalence of anaemia in the control group was in accordance with results published elsewhere (Cook et al, 1976). Why the dancers had more anaemia is not clear. It seems evident that a closer look at their diets should be made. Endurance training is known to increase plasma volume and thus cause dilution anaemia (Hallberg and Magnusson, 1984). This might partly explain the higher prevalence of low haemoglobin concentration in dancers.

Our present data of active dancers' iron balance are in accordance with that of Marino and King (1980), who postulate that female adolescents training strenuously need iron supplementation. This should be taken into account in dance classes and sport clubs. On the other hand iron is the only nutritional supplement recommended for active athletes (Smith, 1982).

Serum ferritin estimation should be used when monitoring iron balance of risk groups of iron deficiency. Iron supplementation therapy, even before anaemia develops, should be used in selected cases to ensure an optimal physical performance. One hundred $\mathrm{mg}$ of elemental iron per day should be enough for iron supplementation (Crosby, 1984). The supplementation therapy should last for several months in order for the iron stores to be increased (Fairbanks and Beutler, 1983).

\section{References}

Cavill, J., 1982 "Disorders of Iron Metabolism. Diagnostic Methods". Clin. Haematol. 11: 259-271.

Cook, J., Finch, C. and Smith, N., 1976 "Evaluation of the Iron Status of a Population". Blood 48: 449-455.

Crosby, W., 1984 "The Rationale for Treating Iron Deficiency Anemia". Arch. Intern.Med. 144: 471-472.

Fairbanks, V. and Beutler, E., 1983 "Iron deficiency" in: Haematology. Ed. W. Williams, E. Beutler, A. Erslev and M. Lichtman. 3rd edition. McGrawHill, New York.

Finch, C., Gollnick, P. and Hlastala, M., 1979 "Lactic Acidosis as a result of Iron Deficiency". J.Clin.Invest. 64: 129-137.

Hallberg, L. and Magnusson, B., 1984 "The Etiology of "Sports Anemia" ". Acta Med.Scand. 216: 145-148.

Haymes, E., Puhl, J. and Temples, T., 1986 "Training for cross-country skiing and iron status". Med.Sci.Sports Exerc. 18: 162-167.

Hunding, A., Jordal, R. and Paulev, P.-E., 1981 "Runners anemia and Iron Deficiency". Acta Med.Scand. 209: 315-318.

Lynch, S. R. and Morck, T. A., 1983 "Iron deficiency anemia" in: Nutrition in Haematology pp. 143-165. Contemporary Issues in Clinical Nutrition 5. Ed. J. Lindenbaum. Churchill Livingstone, New York.

Marino, D. D. and King, J. C., 1980 "Nutritional concerns during adolescence". Pediatr.Clin. North Am. 27: 125-139.

Pakarinen, A. and Heikkinen, J., 1985 "The iron balance of ice-hockey players" (in Finnish). Lääkeuutiset 2: 126-128.

Remes, K., 1985 "Need for iron in physical exercise" (in Finnish). Suomen Lăăkăril 40: 2885-2888.

Räsänen, L., Ahola, M., Kimppa, S. and Akerblom, H., 1985 "Results from a multicenter study of nutrition of children and adolescents" (in Finnish). Suomen Lääkäril 40: 2789-2796.

Saris, W. and Brouns, F., 1986 "Nutritional Concerns for the Young Athlete" in: Children and Exercise XII. Int. Series on Sports Sciences, Vol. 17. Ed. J. Rutenfranz, R. Mocellin and F. Klimt. Human Kinetics Publ.Inc. Illinois.

Smith, N. J., 1982 "Nutrition and the Adolescent Athlete". Curr.Concepts Nutr. 11: 63-70. 